\title{
The hippocampus and cue utilization
}

\author{
GORDON WINOCUR \\ Trent University, Peterborough, Ontario K9J 7B8, Canada
}

\begin{abstract}
Animals with hippocampal lesions are typically impaired on tasks which incorporate a large interference component. Thus, they are deficient in tests of learning which require the suppression of a previously learned response (e.g., runway passive avoidance) or the correct selection of a response from among several alternatives (e.g., multiple-arm radial maze). Similarly, their memory for learned habits is adversely affected by conflicting experiences that intervene between original learning and recall. However, when the salience of relevant task-related cues is increased so as to enhance the discriminability between competing associations, performance improves dramatically. It is proposed that damage to the hippocampus results in a general information-processing deficit that is related to an impaired use of available stimulus cues.
\end{abstract}

A plethora of research in the last 20 years has greatly enhanced our understanding of the nature of hippocampal function. As far as the lesion literature is concerned, a clear pattern has emerged with respect to the types of behavioral deficits associated with hippocampal damage (see O'Keefe \& Nadel, 1978). Animals with bilateral hippocampal lesions typically display abnormal behavior under conditions of high interference, as in tasks requiring the acquisition of a new response following incompatible training in a related test situation. This is the case, for example, in standard runway tests of passive avoidance conditioning and extinction, reversal learning, and negative transfer tests involving stimulus shifts along a given dimension. Hippocampal animals are reliably impaired on these tasks, as they are on multiplechoice mazes that require the organization of sequential response patterns in the presence of conflicting stimulus information. Other recent examples of hippocampal deficits in high-interference situations include the latent inhibition paradigms of Solomon and Moore (see Solomon, in press) and Olton's spatial discrimination experiments with the multiplearm radial maze (Olton, 1970). Paradoxically, hippocampal lesions occasionally result in what appears to be superior performance in certain highinterference situations. For example, in two-way active avoidance conditioning, where successful performance depends on returning to areas previously associated with punishment, normal animals tend to show longer response latencies than hippocampals and, consequently, slower avoidance learning.

\footnotetext{
The research reported in this paper has been supported by grants from the National Research Council and the Medical Research Council of Canada. Numerous colleagues and students over the years have contributed in various ways to the research and ideas in this paper and I thank them for their help. Especially, there was Abe Black, for whom there cannot be enough thanks.
}

This pattern, along with the general tendency of hippocampal animals to perseverate inappropriate behaviors, was at first widely attributed to disruption of an inhibitory neural system essential to effective response control (Altman, Brunner, \& Bayer, 1973; Douglas, 1967; Kimble, 1968). However, numerous demonstrations of normal response inhibition by hippocampal animals and deficits on other tasks that could not be attributed to response disinhibition have undermined this position. In recent years, there has been a shift towards more cognitively oriented interpretations that have implicated the structure in various types of information processing. For example, O'Keefe and Nadel (1978) stress the hippocampus's importance in spatial discrimination, Solomon (1979) emphasizes temporal information processing, and Hirsh (1974) has proposed that the hippocampus is primarily involved in the use of contextual cues.

We have also argued that the hippocampal syndrome reflects a basic processing deficit, but our position has been that the impairment is more general than that advocated by other investigators. Animals with hippocampal lesions are seen as limited in their ability to extract information from their environments and, as a result, are more vulnerable to the effects of interference when relevant stimuli are spatially or temporally dissociated or rendered ambiguous by conflicting experiences. In assessing this hypothesis, we have developed a research program in which rats with hippocampal damage are tested under different conditions of cue salience. We have found that when relevant cues are rendered more distinctive, typically observed impairments can be reduced, with performance frequently attaining the level of that of normal animals. The research sampled in this review focuses primarily on the learning and memory capabilities of hippocampal animals as measured in three behavioral tasks-maze learning, 
passive avoidance conditioning, and discrimination learning.

\section{Maze Learning}

In an early experiment in this series (Winocur \& Breckenridge, 1973), groups of rats were tested on a sequential maze consisting of a long runway divided into six compartments separated by panels that contained two doors beside each other. A startbox and a goalbox were located at opposite ends. The correct response pattern leading to the goalbox was determined simply by locking one of each pair of doorsfor this experiment, a L-R-L-R-R-L pattern was designated correct. As expected, hippocampal animals were severely impaired in learning this sequence, requiring an average of 156 trials to reach criterion compared to about 45 trials for controls. However, when discriminative visual stimuli were applied to each door, hippocampal groups improved, and when the stimuli were highly salient, they actually performed as well as control groups. (See Table 1.)

Recently, we have tested the effects of differential cuing using David Olton's eight-arm spatial maze. Figure 1 shows our version of the maze, which essentially is a replica of that originally described by Olton and Samuelson (1976), with all dimensions the same. A major difference is that our maze is surrounded on all four sides by unpainted plywood walls that extend about $2 \mathrm{ft}$ above the top of the maze. The purpose of this modification was to minimize the presence of distal stimuli which could direct the animal's behavior. Figure 1a represents the maze as it appears during standard (noncued) testing. In the cued condition, the discriminability of the arms was enhanced by covering each with a different visual stimulus (Figure 1b). Thus, instead of having to master the task on the basis of spatial cues, the animals could use different visual patterns as cues.

The procedure, after habituation and some pretraining, was to bait the end of each arm with food and allow the animal to choose freely until all eight arms had been chosen or until $10 \mathrm{~min}$ had elapsed. Each rat was tested for a minimum of 10 days and up to 20 days if a criterion of seven correct responses in the first eight choices for 5 consecutive days was not attained. In fact, no additional information was obtained after 10 days, and so only data from the first 10 days of testing will be presented.

These experiments also included groups of rats with lesions to the anterodorsal and posteroventral caudate nucleus, two regions which, along with the hippocampus, have also been implicated in spatial functions. Table 2 presents, for all groups, the mean number of correct responses in the first eight choices of each day's trial over the 10-day test period and the average number of errors/trial over the 10 test days. In the noncued condition, as expected, the hippo-
Table 1

Mean Trials to Criterion for Hippocampal,

Cortical, and Operated Control Groups in Original Maze Learning

\begin{tabular}{lrrrcc}
\hline \multicolumn{1}{c}{ GROUP } & COMDITION 1 & CONDITION 2 & CONDITION 3 & CONDITION 4 & CONDITION 5 \\
\hline \multirow{2}{*}{ HIPPOCMMPAL } & 156.0 & 77.8 & 70.0 & 57.5 & 13.8 \\
CORTICAL & 44.0 & 26.0 & 28.3 & 27.5 & 13.3 \\
OPERATED CONTROL & 47.0 & 23.0 & 20.0 & 26.3 & 15.0 \\
\hline
\end{tabular}

Table 2

Performance of Groups on Cued and Noncued Versions of the Eight-Arm Radial Maze

HIPPOCAMPAL AD CAUDATE PV CAUDATE CORTICAL CONTROL

$\begin{array}{lccccc}\bar{x} \text { CORRECT/ } & & & & & \\ \text { 1ST } 8 & 5.80 & 6.58 & 6.68 & 6.86 & 7.00 \\ \text { CHOICES } & & & & & \\ \begin{array}{l}\bar{x} \text { ERRORS/ } \\ \text { TRIAL }\end{array} & 8.19 & 4.04 & 3.38 & 2.58 & 1.86\end{array}$

\begin{tabular}{lccccc}
$\overline{5}$ & CUED & & & \\
$\begin{array}{l}\bar{x} \text { CORRECT/ } \\
1 \text { ST } 8\end{array}$ & 6.76 & 7.19 & 6.88 & 6.92 & 7.02 \\
$\begin{array}{l}\text { CHOICES } \\
\bar{x} \text { ERRORS/ }\end{array}$ & 3.40 & 1.84 & 3.08 & 2.52 & 2.12 \\
\hline TRIAL & 3.08 & & & &
\end{tabular}

Note-AD, anterodorsal; $P V$, posteroventral.

campal group was severely impaired relative to all other groups on both measures. This result essentially replicates that of David Olton, who made fornix lesions in his animals, and that of Len Jarrard (1978), who found that the hippocampal deficit was principally the result of damage to subarea $\mathrm{CA}_{1}$. The anterodorsal and posteroventral caudate groups were impaired relative to the operated controls, although both caudate groups performed significantly better than hippocampals on both measures.

In the cued condition, there was a significant improvement in the hippocampal and anterodorsal caudate groups. The posteroventral caudate group did not improve over its noncued counterpart, and there was also no overall change in the performance of the cortical and operated control groups. Comparing between groups in the cued condition, there were no differences in terms of the average number of correct responses, so, clearly, the visual cuing was a significant equalizer in this respect. As for error scores, there were no differences between anterodorsal caudate, cortical, and operated control groups-the anterodorsal group clearly benefited from the cues. The hippocampal group, despite a significant improvement relative to the noncued hippocampals, still made more errors than the anterodorsal caudate and control groups. The posteroventral caudate animals made about as many errors as the hippo- 

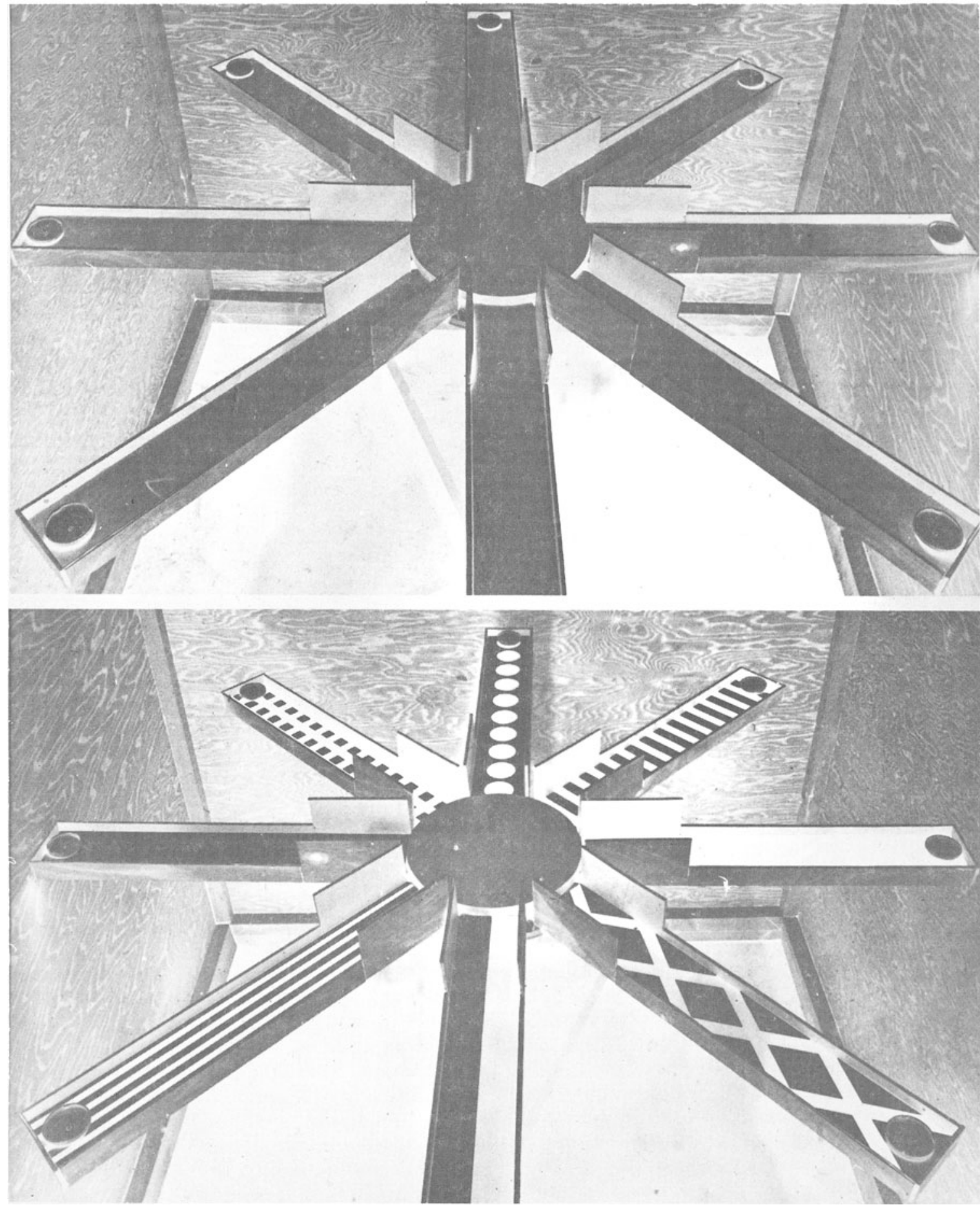

Figure 1. Eight-arm radial maze. Above: standard, noncued version. Below: cued version.

campal group and significantly more than the anterodorsal caudate and operated control groups.

These results suggest that the hippocampus and the caudate nucleus both contribute to efficient maze performance but probably in different ways. It has been suggested that the posteroventral caudate nucleus contributes in a nonspecific way to the organization of behavior (Winocur, 1974). The impairments of the posteroventral groups in both mazes and their failure to improve in the cued condition support this interpretation, but the relationship of the deficit to input and output mechanisms is not 
clear at this point. The anterodorsal caudate deficit was more selective, since it was apparent only in the noncued maze. The normal performance of anterodorsal animals in the cued maze suggests that complex visual discriminative capacities were intact and that their deficit was primarily spatial in nature.

The hippocampals' performance in the noncued maze also suggests a spatial dysfunction, but the fact that they still made more errors than control groups in the cued maze indicates a residual impairment quite likely related to the nature of the visual discrimination inherent to the task. This view is consistent with the notion that the hippocampus is important for processing not only spatial cues, but stimulus information generally.

It is generally assumed that animals normally discriminate and select arms in the radial maze on the basis of spatial cues. The possibility exists, however, that the eight-arm maze is not, in fact, a spatial task and that animals learn the maze on the basis of response-produced cues. The impairment of braindamaged animals would thus be attributed to their having adopted less efficient response sequence strategies, resulting in greater numbers of tracings (Note 1). If this is so, then hippocampal and normal rats should display different response patterns in solving the task and, in fact, Olton and Werz (1978) have provided some evidence that this is, in fact, the case, at least for a 17-arm version of the maze.

Accordingly, we analyzed response patterns by quantifying, for each response, the arm selected as a function of the arm just chosen. Thus, if the animal retraced the previously selected arm, a score of 0 was given. Choosing the immediately adjacent arm on either side resulted in a score of 1 , and so on. No differences were found in terms of left or right turns, and so, for purposes of simplification, data are presented without regard to direction. The number of choices made to each position was calculated and expressed as a percentage of total choices (Figure 2).

As can be seen from the graph, there is little evidence that response distributions differed between groups. In both conditions, the second and third arms away from the one just chosen were generally the most frequently selected. Although the respective patterns in the noncued condition indicated a peak at the second position for the control group and at the third position for the hippocampal group, statistical analyses revealed no significant differences here or in the cued condition, where the patterns were virtually identical.

We have also experimented with the effects of preoperatively training rats on either the cued or non-

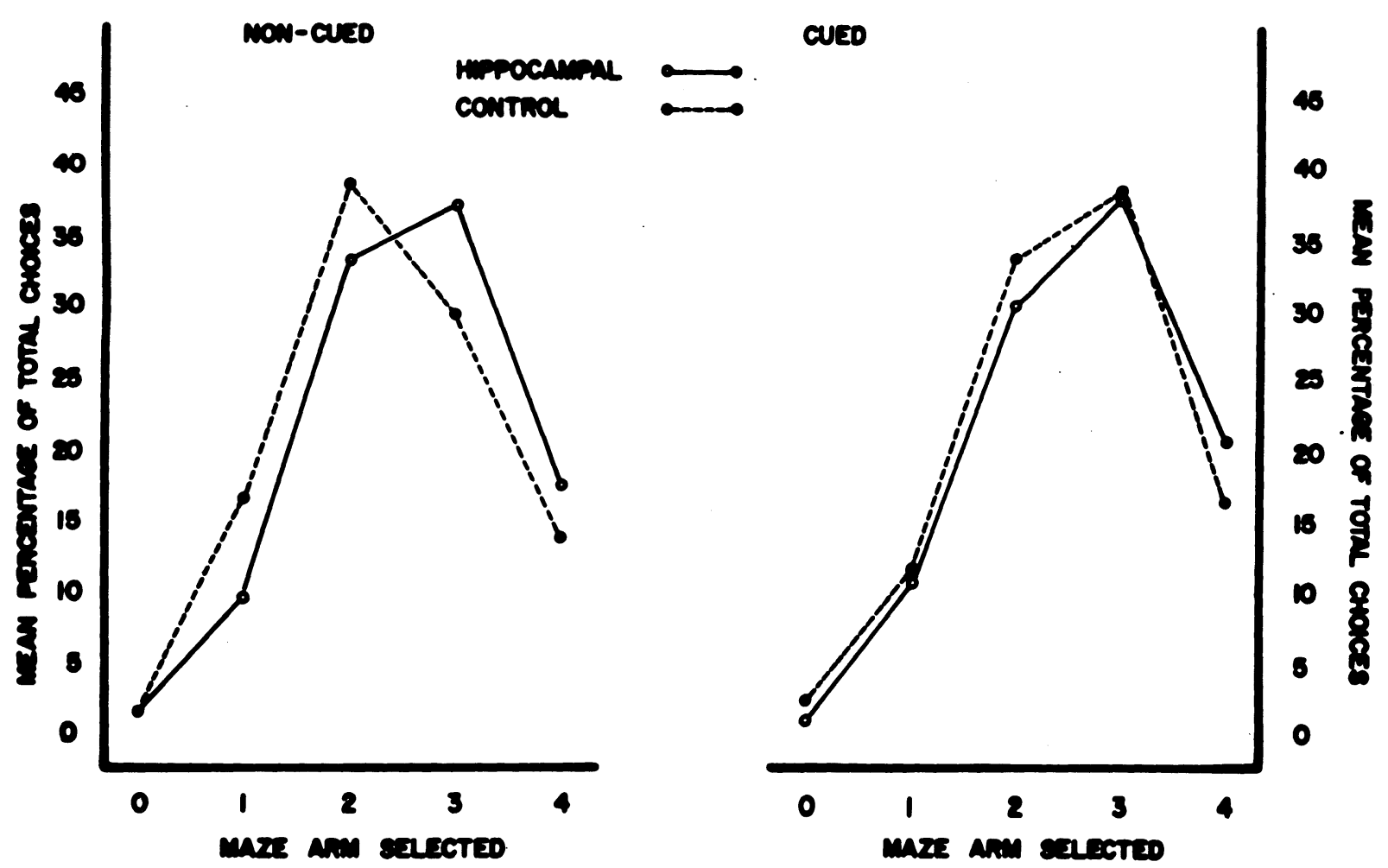

Figure 2. Response distributions of hippocampal and control groups in noncued and cued versions of the eight-arm radial maze. 
cued version of the maze and then testing them postoperatively on either the same or the other version. Of particular interest here were the effects of preoperative experience with the noncued maze. If hippocampal lesions wipe out the ability to use spatial strategies, as argued, for example, by O'Keefe and Nadel, then preoperative experience with such a strategy should have minimal consequences for postoperative performance in either maze. In fact, the results showed that hippocampal performance on the cued maze deteriorated following preoperative training on the noncued version (see Table 3). Postoperative performance by hippocampals in the noncued maze was poor and apparently unaffected by prior training on that maze. Interestingly, the anterodorsal caudate group seemed to behave more in line with the predictions of a spatial hypothesis, since they failed to show the effects of preoperative training in either condition.

One interpretation of these results, as far as the hippocampus is concerned, derives from evidence that hippocampal animals have great difficulty in breaking away from conflicting habits previously acquired within the same general context. Thus, having preoperatively learned the task on the basis of spatial cues, hippocampals attempted to employ the same strategy postoperatively despite the presence of visual cues. Their poor performance might simply reflect an impaired ability to deal with spatial information.

Alternatively, if one takes the position that the maze is learned on the basis of response-produced cues, it could be argued that the negative transfer by hippocampal animals in the noncued/cued condition reflects an impairment in shifting from a response strategy to a strategy controlled by visual cues. This possibility is being assessed in an ongoing

Table 3

Performance of Groups in Preoperative Noncued Transfer Conditions

\begin{tabular}{|c|c|c|c|c|}
\hline \multicolumn{5}{|c|}{ NON-CUED/CUED } \\
\hline & $\bar{x}$ CORRECT. & $\bar{x}$ ERRORS & $\bar{x}$ CORRECT & $\bar{x}$ ERRORS \\
\hline HIPPOCAMPAL & 6.93 & 2.37 & 5.89 & 8.50 \\
\hline aD caudate & 6.91 & 2.27 & 6.93 & 2.43 \\
\hline PV caudate & 6.80 & 1.62 & 6.45 & 5.88 \\
\hline CORTICAL & 6.69 & 3.46 & 6.94 & 2.82 \\
\hline OP CONTROL & 6.99 & 3.03 & 7.24 & 1.54 \\
\hline \multicolumn{5}{|c|}{ NON-CUED/NON-CUED } \\
\hline HIPPOCAMPAL & 6.78 & 2.68 & 5.96 & 6.80 \\
\hline AD CAUDATE & 6.88 & 2.56 & 6.20 & 4.10 \\
\hline PV CAUDATE & 6.80 & 2.43 & 6.44 . & 4.90 \\
\hline CORTICAL & 6.98 & 2.55 & 6.98 & 2.30 \\
\hline OP CONTROL & 7.02 & 2.36 & 7.15 & 2.10 \\
\hline
\end{tabular}

Note-AD, anterodorsal; $P V$, posteroventral; $O P$, operated. study in which animals are prevented from using response-produced cues in either pre- or postoperative learning of the maze. Using a procedure similar to that described by Olton and Werz (1978), the animal is restricted to the center of the apparatus for $15 \mathrm{sec}$ after returning from the previously selected arm and before the next response. This is accomplished by lowering a cylinder so as to block access to any of the goal arms. At the end of the confinement period, the cylinder is raised and the animal is allowed to choose freely among all the arms. Animals are very active during confinement, so when the barrier is removed, they could be facing any of the arms. Olton and Werz found that this had the effect of disrupting systematic response patterning in all animals, forcing an exclusive dependency on environmental cues.

A few animals have now been postoperatively tested in the cued maze with or without preoperative training in the noncued maze. At this point, our results are exactly the same as in the nonconfinement experiments-hippocampal performance, which is good without prior training, deteriorates following training on the noncued maze. We also found, as did Olton and Werz, that this procedure eliminated the response patterning observed in the other experiments. Clearly, then, the hippocampals' dependency on spatial cues was interfering with their ability to transfer to a strategy involving the visual cues. The data suggest that animals with hippocampal lesions at least attempt to deal with spatial cues but that they do so very inefficiently.

\section{Passive Avoidance Conditioning}

In standard runway tests of passive avoidance, animals are initially trained to run down an alley for a particular reward. After the response has stabilized, electric shock is introduced in the goalbox; for normal animals, this acts as a deterrent against running on subsequent trials. Animals with hippocampal damage readily learn the approach response but are impaired in withholding that response following punishment. This result has been taken as strong support for a response disinhibition interpretation of hippocampal function. However, careful examination of hippocampals' performance in passive avoidance testing reveals that, in fact, they do exhibit response suppression but not at the same point in the runway as controls. In a standard runway, controls usually inhibit approach behavior shortly after they leave the start area, while hippocampals do not show response inhibition until they are about two-thirds of the way down the alley. Typically, there is no difference between hippocampal and control groups in the number of goalbox entries after punishment has been experienced. Thus, rats, with hippocampal lesions are responsive to goalbox cues associated with punishment but are unable to link their aversive exper- 
ience to more remote cues at the beginning of the runway.

Taking the approach that the passive avoidance deficity of hippocampal animals reflects a dysfunction in cue utilization, attempts were made in a number of experiments to upgrade their performance by enhancing the salience of task-related cues. In the first study (Winocur \& Bindra, 1976), this was accomplished by locating contextual features directly associated with the goalbox earlier in the runway. The distinctive white-walled goalbox was a standard 6-in. length in the control condition but extended back to the midpoint of the otherwise gray runway in the experimental condition. The results were quite clear. In both conditions, hippocampals quickly ran out of the startbox and did not slow down until they approached the white walls. This finding points once again to the hippocampal animal's need for more salient information in a high-interference task where available cues ambiguously signal conflicting responses.

A different cuing procedure was employed in a follow-up study (Winocur \& Black, 1978). The rationale was that if the passive avoidance deficit of hippocampal animals was the result of not integrating the aversive experience in the goalbox with events in the startbox, this process might be facilitated by providing the animals with appropriate reminder cues prior to being placed in the startbox for avoidance testing. The procedure was to train animals in the usual way to approach the white goalbox for water reward prior to shock. On the postshock day, $2 \mathrm{~h}$ before a single no-shock trial was administered, animals were placed individually, for $2 \mathrm{~min}$, in a replica of the goalbox with or without accompanying electric shock or in a neutral Plexiglas box without shock.

Figure 3 shows the results, which, for the last preshock trial and the last shock trials, are generally as expected. On the test trial, hippocampal animals continued to show poor response suppression in the neutral box condition. However, there was a dramatic improvement in hippocampal passive avoidance following the other reminders where no difference was found between hippocampal and control groups on the test trial. One interpretation of this result is that the reminders had the effect, for hippocampal animals, of reinstating stimuli that had been associated with shock, thereby increasing the number of discriminative stimuli available to them in the startbox.

The most recent experiments in this series have been employing brain stimulation as a reminder cue. The studies are still under way, but some clear emergent trends can be reported. We have found, for example, that $2 \mathrm{~h}$ before passive avoidance recall testing, aversive brain stimulation applied to the medial thalamus can be as effective a reminder as
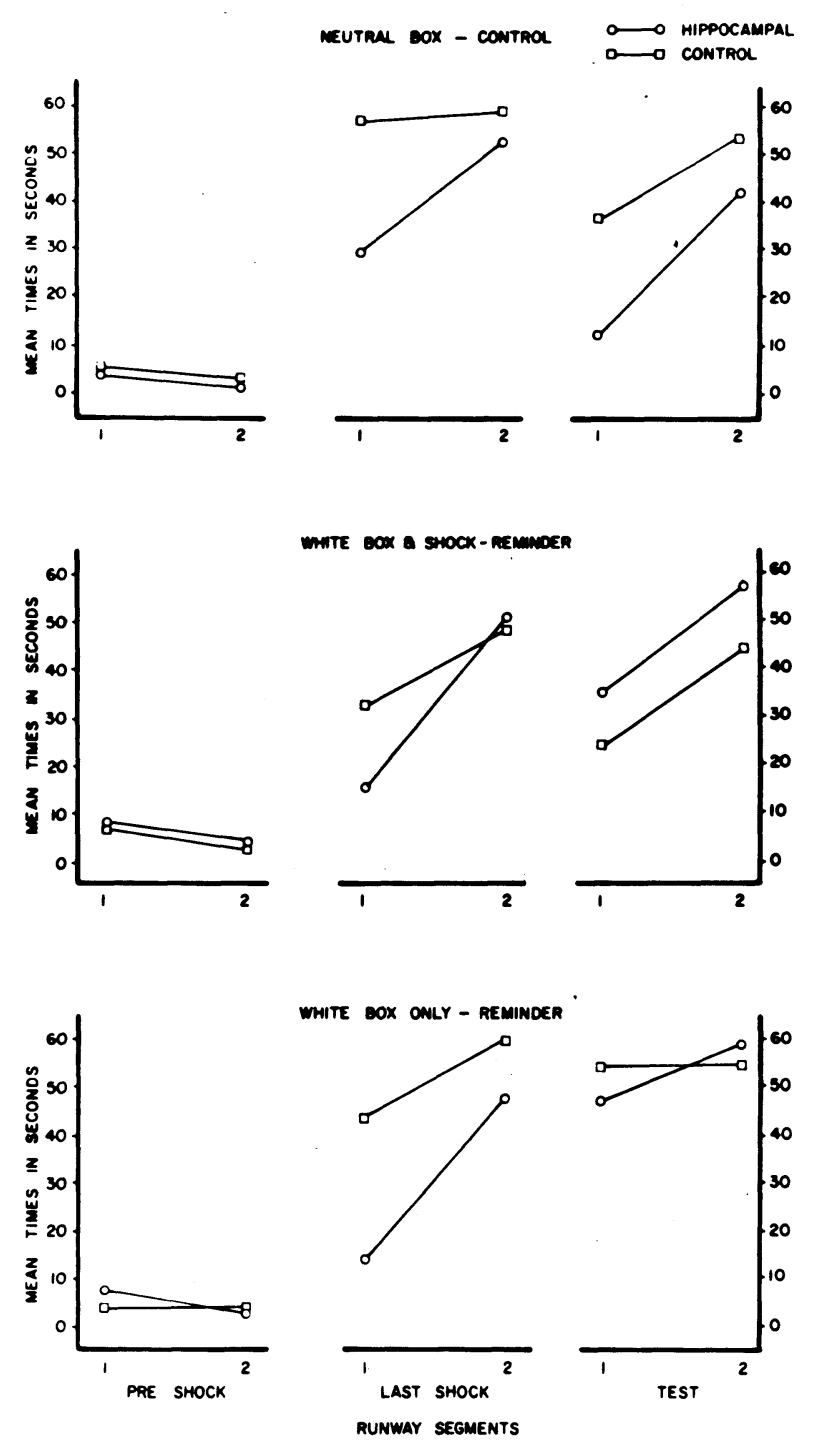

Figure 3. First- and second-half runway latencies for hippocampal and control groups in the last preshock trial, the last shock trial, and the recall test trial under three reminder conditions. (Winocur \& Black, 1978, reproduced by permission).

stimuli directly associated with the aversive experience in the goalbox. On the other hand, positively rewarding brain stimulation applied to the medial forebrain bundle did not alter the hippocampals' tendency to approach the goalbox (Table 4). Other positive and negative brain sites, particularly in the area of the medial lemniscus, have now been studied with identical results. The passive avoidance behavior of control animals appears to be unaffected by either type of brain stimulation-they continue to display good response suppression early in the runway.

Another brain area known to play a role in passive avoidance learning is the septum. The brain stimulation experiments have also been conducted on rats with septal lesions and have obtained an entirely different pattern of results. Septal groups showed 
Table 4

Mean Approach Latencies in Runway Segments 1 and 2 Following Negatively or Positively Reinforcing Brain Stimulation

MEDIAL THALAMUS STIMULATION

\begin{tabular}{|c|c|c|c|c|}
\hline I PPOCAMPAL & \multicolumn{2}{|c|}{ CORTICAL } & \multicolumn{2}{|c|}{ OPERATED CONTROL } \\
\hline 2 & 1 & 2 & 1 & 2 \\
\hline 60 & 45.1 & 60 & 24.3 & 60 \\
\hline
\end{tabular}

MEDIAL FOREBRAIN BUNDLE STIMULATION

\begin{tabular}{cccccc}
\multicolumn{2}{c}{ HIPPOCAMPAL } & \multicolumn{2}{c}{ CORTICAL } & \multicolumn{2}{c}{ OPERATED CONTROL } \\
1 & 2 & 1 & 2 & 1 & 2 \\
15.4 & 30.2 & 46.8 & 59.8 & 46.3 & 49.8 \\
\hline
\end{tabular}

strong response perseveration under all conditions. Currently, studies are being conducted in which the passive avoidance behavior of septal animals is being examined, using the types of reminder cues developed for the Winocur and Black study.

As far as the hippocampus is concerned, the brain stimulation data appear to implicate the structure in mediational processes, since, in this case, the previously unavailable avoidance response was activated by aversive stimulation entirely different from that experienced during testing. The suggestion that the hippocampus may be involved in integrating disparate events has, to my knowledge, not been made before and warrants further study. The notion, however, is quite consistent with the type of cue-utilization hypothesis advocated in this paper.

\section{Discrimination Learning and Recall}

The cue-utilization hypothesis has proven useful in resolving what appeared to be a major contradiction between the animal and human literature with respect to hippocampal involvement in memory processes. Since the work of Milner and her colleagues (1965), the hippocampus has been linked to the mediation of normal human memory, but attempts to demonstrate a similar relationship in animals were consistently unsuccessful (see Isaacson, 1975). Although this may be taken as evidence of discontinuity in the comparative development of hippocampal function, closer examination of the respective literatures reveals significant differences in testing procedures across species which could account for the apparent contradiction. In contrast to human experiments, where the potential for interference is considerable, in animal tests of memory special care is usually taken to ensure that original learning and recall conditions are as identical as possible. Moreover, the distinctive character of the novel learning situation and the absence of distraction between test sessions facilitate retrieval processes by minimizing interfering influences. This suggests that the apparently normal memory of hippocampal animals may simply be the result of having available, at recall, all the cues associated with a highly distinctive learning situation. These observations led to the prediction that manipulations that significantly alter the stimulus situation at retesting and require the animal to reconstruct the original task on the basis of incomplete cues should have an adverse effect on hippocampals' ability to remember the learned habit.

This was demonstrated in one experiment by varying contextual conditions associated with the learning and recall of a simultaneous visual discrimination habit (Winocur \& Olds, 1978). In context A, animals were motivated by food reward and tested in a discrimination chamber painted flat gray and located in a room with standard illumination and noise levels. The experimenter wore a black Viyella lab coat and cotton gloves while handling the rats. In context B, a new apparatus, made of chip board, painted silver, and lined with wire mesh, was located in a different room which was dark except for a $15-\mathrm{W}$ light located over the discriminanda. Taped music was played throughout all shaping and testing. In this condition, animals were water deprived and correct responses were rewarded by 10 -sec access to a water bottle. The animals were run by the same experimenter, who this time wore a white cotton lab coat and no gloves. The basic design of the experiment was to train hippocampal and control groups of rats on the discrimination habit in either context $\mathrm{A}$ or context $\mathbf{B}$ and then subsequently test their recall and relearning abilities in either the same or the other contextual condition. The discriminanda were, of course, the same in both conditions.

Table 5 shows that all groups learned the original discrimination at about the same rate regardless of context. Furthermore, the control groups showed excellent savings at retesting under all conditions. The hippocampals, although showing good recall in the nonshift condition, were markedly impaired in the shift condition, both in terms of trials to relearn criterion and percentage savings. These data reflect the limited flexibility of hippocampal animals and their exaggerated dependence on contextual cues to define a learning situation. In contrast, the control

Table 5

Mean Learning and Recall Scores for All Groups in Context Shift Experiment

\begin{tabular}{|c|c|c|c|c|c|c|c|c|c|}
\hline & \multicolumn{3}{|c|}{ HIPPOCAMPALS } & \multicolumn{3}{|c|}{ CORTICALS } & \multicolumn{3}{|c|}{ OPERATED CONTROLS } \\
\hline & $\begin{array}{l}\text { ORIGIMUL } \\
\text { LEARMING } \\
\end{array}$ & $\begin{array}{l}\text { RE- } \\
\text { LEARMING } \\
\end{array}$ & $\begin{array}{l}z \\
\text { SAVINGS }\end{array}$ & LEARNING & $\begin{array}{l}\text { RE- } \\
\text { OEARNING }\end{array}$ & SAVINGS & LEARNING & $\begin{array}{l}\text { RE- } \\
\text { LEARN ING }\end{array}$ & $\bar{l}$ \\
\hline \multicolumn{10}{|c|}{ SHIFT } \\
\hline$A B$ & 40 & 16.7 & 53.2 & 34 & 4.0 & 86.7 & 47.5 & 4.0 & 90 \\
\hline $\mathrm{BA}$ & 40 & 12.5 & 56.5 & 52 & 6.0 & 88.6 & 37.5 & 2.5 & 93.8 \\
\hline $\bar{x}$ & 40 & 14.3 & 55.1 & 43 & 5.0 & 87.6 & 42.5 & 3.8 & 91.9 \\
\hline \multicolumn{10}{|c|}{ NO-SHIFT } \\
\hline$A A$ & 46 & 2.0 & 95 & 37.5 & 10.0 & 70.8 & 44 & 0 & 100 \\
\hline BB & 33.3 & 1.7 & 91.7 & 38.0 & 4.0 & 90.0 & 41.7 & 0 & 100 \\
\hline $\bar{x}$ & 39.1 & 1.8 & 93.2 & 37.8 & 6.7 & 81.5 & 42.7 & 0 & 100 \\
\hline
\end{tabular}


animals were unresponsive to contextual manipulations, indicating that they were able to derive sufficient information about the task using only primary discriminanda.

The results are consistent with the cue-utilization hypothesis, which predicts that hippocampal lesions, by impairing animals' ability to extract information from stimuli, would force greater reliance on secondary cues. However, they do not appear compatible with Hirsh's (1974) contextual-retrieval notion of hippocampal function. According to Hirsh, the intact hippocampus is essential for using contextual cues for purposes of selective retrieval. When the hippocampus is damaged, the animal's ability to use contextual cues is expected to be impaired. Our data seem to indicate the opposite, namely that hippocampal animals use contextual cues even more than do normals.

In another test of the memory capabilities of hippocampal animals, an experiment was conducted using a retroactive interference paradigm similar to that frequently used in human research (Winocur, 1979). Animals initially learned to discriminate between horizontal and vertical stripes for food reward and were then subjected to one of three interference conditions for 5 days before recall testing. In Condition UP, the animals were administered an unsolvable problem in which the original stimuli were replaced by diagonal stripes arranged in mirror image to each other. On half the daily trials, both doors were locked, while on the other half, both doors were closed but unlocked. The designations of the trials in which the doors were locked or not was determined randomly and independently of the stimulus arrangement. Thus, the animals' responses were rewarded on $50 \%$ of the choices made. In Condition RT, the groups received 10 reinforced trials per day in the apparatus with both goal doors unlocked and open and food always available. No stimuli were affixed to the doors, which were painted flat gray, as was the rest of the apparatus. The remaining groups assigned to Condition NT received no interpolated trials or exposure to the apparatus, but were removed once each day from their cages and fed in the usual manner on the feeding stand. On the 6th postcriterion day, the animals began relearning the discrimination following the original testing procedures.

The results of this experiment are presented in Table 6. All groups learned the original discrimination within normal limits, and similarly there were no relearning differences in the relatively low interference RT and NT conditions. There was, however, a significant effect in the UP condition where the hippocampals required more trials to reestablish criterion and showed less percentage savings than the control groups.
Table 6

Mean Scores for All Groups in the Test of Retroactive Interference

\begin{tabular}{lrrrrrrrrrr}
\hline & \multicolumn{3}{c}{ HIPPOCAMPAL } & \multicolumn{3}{c}{ CORTICAL } & \multicolumn{3}{c}{ OPERATED CONTROL } \\
& UP & RT & NT & UP & RT & NT & UP & RT & NT \\
\hline $\begin{array}{l}\text { ORIGINAL } \\
\text { LEARNING }\end{array}$ & 43.3 & 52.5 & 56.0 & 43.3 & 58.3 & 55.0 & 46.0 & 65.0 & 46.7 \\
$\begin{array}{l}\text { RELEARNING } \\
\begin{array}{l}\text { PERCENT } \\
\text { SAVINGS }\end{array}\end{array}$ & 30.0 & 3.8 & 3.3 & 10.1 & 5.0 & 3.3 & 6.0 & 1.7 & 5.0 \\
\hline
\end{tabular}

Note-UP, unsolvable problem; $R T$, reinforced trials; $N T$, no trials.

\begin{tabular}{|c|c|c|c|c|c|c|c|c|c|}
\hline \multicolumn{10}{|c|}{$\begin{array}{c}\text { Table } 7 \\
\text { Mean Scores for All Groups in the } \\
\text { Test of Proactive Interference }\end{array}$} \\
\hline & \multicolumn{3}{|c|}{ HIPPOCAMPAL } & \multicolumn{3}{|c|}{ CORTICAL } & \multicolumn{3}{|c|}{ OPERATED CONTROL } \\
\hline & UP & RT & NT & UP & RT & NT & UP & $R T$ & NT \\
\hline $\begin{array}{l}\text { ORIGIMAL } \\
\text { LEARMIMG }\end{array}$ & 126.7 & 65.7 & 41.7 & 75.0 & 43.7 . & 48.0 & 62.0 & 48.0 & 36.2 \\
\hline RELEARNING & 8.3 & 7.1 & 3.3 & 5.0 & 5.0 & 2.0 & 2.0 & 4.0 & 6.0 \\
\hline $\begin{array}{l}\text { PERCENT } \\
\text { SAVINGS }\end{array}$ & 93.4 & 90.2 & 91.7 & 93.1 & 91.0 & 96.0 & 96.7 & 96.7 & 87.0 \\
\hline
\end{tabular}

Note-UP, unsolvable problem; $R T$, reinforced trials; $N T$, no trials.

In a subsequent experiment, using a proactive interference paradigm, we found that the disruptive effects of high interference extend also to acquisition of a discrimination habit. In this study, animals were subjected to one of the three interference conditions before original learning, which in turn was followed by a retention test. As can be seen in Table 7, the hippocampal group in the UP condition was impaired in learning the discrimination.

The animal data parallel in an interesting way the well-established learning and memory deficits of human amnesics with known or suspected hippocampal damage. In our own human research, we have also found that when interfering influences are reduced through the use of various cuing techniques, performance improves significantly (Winocur \& Kinsbourne, 1978; Winocur \& Weiskrantz, 1976). We have suggested that a likely effect of cuing, particularly in instances of high retroactive and proactive interference, is to enhance the differentiating characteristics of competing associations, resulting in more efficient learning or retrieval strategies. Thus, one may speculate that the human amnesic and animal hippocampal syndromes equally represent a fundamental misuse of information, thereby providing the basis of a unifying theoretical framework for hippocampal function.

\section{Summary and Conclusions}

The results of our research have focused attention on the learning and memory deficiencies of animals with hippocampal damage under conditions of high interference. The basic difficulty was interpreted as 
an inability to derive sufficient cue value from environmental stimuli for purposes of forming appropriate behavioral strategies. In tests of learning following incompatible training, hippocampal animals appear to remain under the control of previous stimulus contingencies to the extent that they frequently perseverate old responses. In tests of memory, hippocampal damage results in poor recall if stimuli associated with the originally learned response are unavailable or rendered less distinctive by distracting interpolated activity. When salient cues are available to provide additional discriminative information and facilitate task identification, hippocampal performance improves dramatically.

The hippocampus is clearly implicated in an information processing function. Other investigators have taken a similar approach, although for the most part greater emphasis has been placed on specific types of processing deficits. The position favored here is that the hippocampus is important for utilizing all types of stimulus cues and that damage to the structure limits this operation, particularly in the presence of ambiguous stimuli.

\section{REFERENCE NOTES}

1. I am grateful to Abe Black for having suggested this interpretation in a personal communication.

\section{REFERENCES}

Altman, J., Brunner, R. L., \& Bayer, F. A. The hippocampus and behavioral maturation. Behavioral Biology, 1973, 8, 557-596.

Douglas, R. J. The hippocampus and behavior. Psychological Bulletin, 1967, 67, 416-442.

Hirsh, R. The hippocampus and contextual retrieval of information from memory: A theory. Behavioral Biology, 1974, $12,421-444$

IsAacson, R. L. Memory processes in the hippocampus. In D. Deutsch \& J. A. Deutsch (Eds.), Short-term memory. New York: Academic Press, 1975.
JARRARD, L. E. Selective hippocampal lesions: Differential effects on performance by rats of a spatial task with pre-operative versus post-operative training. Journal of Comparative and Physiological Psychology, 1978, 92, 1119-1127.

Kimble, D. P. Hippocampus and internal inhibition. Psychological Bulletin, 1968, 70, 285-295.

Milner, B. Memory disturbance after bilateral hippocampal lesions. In P. Milner \& S. Glickman (Eds.), Cognitive processes and the brain. New York: Van Nostrand, 1965.

O'Keefe, J., \& Nadel, L. Hippocampus as a cognitive map. London: Oxford University Press, 1978.

Olton, D. S. The function of septo-hippocampal connections in spatially organized behavior. In Functions of the septohippocampal system, CIBA Foundation Symposium. Amsterdam: Elsevier, 1970.

Olton, D. S., \& Samuelson, R. J. Remembrance of places passed: Spatial memory in rats. Journal of Experimental Psychology: Animal Behavior, 1976, 2, 97-116.

Olton, D. S., \& Werz, M. A. Hippocampal function and behavior: Spatial discrimination and response inhibition. Physiology \& Behavior, 1978, 20, 597-605.

Solomon, P. R. Temporal versus spatial information processing theories of hippocampal function. Psychological Bulletin, 1979, 86, 1271-1279.

Winocur, G. Functional dissociation within the caudate nucleus of rats. Journal of Comparative and Physiological Psychology, 1974, 86, 432-439.

Winocur, G. The effects of interference on discrimination learning and recall by rats with hippocampal lesions. Physiology \& Behavior, 1979, 22, 339-345.

Winocur, G., \& Bindra, D. Effects of additional cues on passive avoidance and extinction in rats with hippocampal lesions. Physiology \& Behavior, 1976, 17, 915-920.

Winocur, G., \& Black, A. H. Cue-induced recall of a positive avoidance response by rats with hippocampal lesions. Physiology \& Behavior, 1978, 21, 39-44.

Winocur, G., \& Breckenridge, C. B. Cue-dependent behavior of hippocampally-damaged rats in a complex maze. Journal of Comparative and Physiological Psychology, 1973, 82, 512-522.

Winocur, G., \& Kinsbourne, M. Contextual cueing as an aid to Korsakoff amnesics. Neuropsychologia, 1978, 16, 671-682.

Winocur, G., \& Olds, J. Effects of context manipulation on memory and reversal learning in rats with hippocampal lesions. Journal of Comparative and Physiological Psychology, 1978, 92, 312-321.

Winocur, G., \& Weiskrantz, L. An investigation of pairedassociate learning in amnesic patients. Neuropsychologia, 1976, 14, 97-110. 